\title{
Case report: characterization of a persistent, treatment-resistant, novel Staphylococcus aureus infection causing chronic mastitis in a Holstein dairy cow
}

Ellie J. Putz ${ }^{1,2}$, Mitchell V. Palmer ${ }^{1}$, Hao Ma², Eduardo Casas², Timothy A. Reinhardt ${ }^{2}$ and John D. Lippolis ${ }^{2 *}$ (D)

\begin{abstract}
Background: Mastitis is the most common health concern plaguing the modern dairy cow and costs dairy producers estimates of two billion dollars annually. Staphylococcus aureus infections are prevalent, displaying varied disease presentation and markedly low cure rates. Neutrophils are considered the first line of defense against mastitis causing bacteria and are frequently targeted in the development of treatment and prevention technologies. We describe a case of naturally occurring, chronic mastitis in a Holstein cow (1428), caused by a novel strain of $S$. aureus that was not able to be cleared by antibiotic treatment.

Case presentation: The infection was identified in a single quarter, 2 months into the cow's first lactation. The infection persisted for the following 20 months, including through dry off, and a second calving and lactation. This case of mastitis was associated with a consistently high somatic cell count, however presented with no other clinical signs. This cow was unsuccessfully treated with antibiotics commonly used to treat mastitis, consisting of two rounds of treatment during lactation and an additional round at the beginning of dry off. The chronic infection was also unchanged through an experimental mid-lactation treatment with pegylated granulocyte-colony stimulating factor (PEG-gCSF) and an additional periparturient treatment with PEG-gCSF. We isolated milk neutrophils from 1428 and compared them to two cows challenged with experimental S. aureus, strain Newbould 305. Neutrophils from 1428's milk had higher surface expression of myeloperoxidase compared to experimental Newbould challenged animals, as well as increased presence of Neutrophil Extracellular Traps. This suggests a heightened activation state of neutrophils sourced from 1428's naturally occurring infection. Upon postmortem examination, the affected quarter revealed multifocal abscesses separated by fibrous connective tissues. Abscesses were most common in the gland cistern and collecting duct region. Microscopically, the inflammatory reaction was pyogranulomatous to granulomatous and consistent with botryomycosis. Colonies of Gram-positive cocci were found within the eosinophilic matrix of the Splendore-Hoeppli reaction within granulomas and intracellularly within the acinar epithelium.

(Continued on next page)
\end{abstract}

\footnotetext{
*Correspondence: john.lippolis@usda.gov

${ }^{2}$ USDA-ARS-National Animal Disease Center, Ruminant Disease and Immunology Research Unit, Ames, IA, USA

Full list of author information is available at the end of the article
}

(c) The Author(s). 2020 Open Access This article is licensed under a Creative Commons Attribution 4.0 International License, which permits use, sharing, adaptation, distribution and reproduction in any medium or format, as long as you give appropriate credit to the original author(s) and the source, provide a link to the Creative Commons licence, and indicate if changes were made. The images or other third party material in this article are included in the article's Creative Commons licence, unless indicated otherwise in a credit line to the material. If material is not included in the article's Creative Commons licence and your intended use is not permitted by statutory regulation or exceeds the permitted use, you will need to obtain permission directly from the copyright holder. To view a copy of this licence, visit http://creativecommons.org/licenses/by/4.0/ The Creative Commons Public Domain Dedication waiver (http://creativecommons.org/publicdomain/zero/1.0/) applies to the data made available in this article, unless otherwise stated in a credit line to the data. 
(Continued from previous page)

Conclusions: Collectively, we describe a unique case of chronic mastitis, the characterization of which provides valuable insight into the mechanics of $S$. aureus treatment resistance and immune escape.

Keywords: Mastitis, Staphylococcus aureus, Dairy, Myeloperoxidase, Antibiotic resistant, Chronic, Splendore-Hoeppli

\section{Background}

Mastitis is estimated to cost the US dairy industry $\$ 2$ billion per year [1]. One of the most common mastitis causing pathogens remains Staphylococcus aureus (S. aureus), which can appear in both chronic and acute varieties, with markedly low cure rates [2, 3]. S. aureus is known to escape immune clearance by adhering and infiltrating epithelial cells of the mammary gland which contributes to the difficulty to treat an infection [4, 5]. S. aureus can also be associated with walled-off aggregates seen histologically as Splendore-Hoeppli phenomena [6]. Strain specific phenotypes are also associated with $S$. aureus infections in cattle, including varying degrees of epithelial invasiveness, and inflammatory responses $[5,7,8]$.

Neutrophils are a primary immune effector cell in response to an intramammary infection [9-11]. Circulating neutrophils express the cell adhesion molecule CD62L (L-selectin) on their cell surface. In response to an infection, local vascular signaling molecules interact with CD62L. This activation causes CD62L to be cleaved and shed from the cell surface, which facilitates cell migration into the tissue and helps target CD62L expressing immune cells, such as neutrophils, to the site of infection [10, 12-14]. An additional adhesion molecule, CD62E (E-selectin), is differentially expressed on vascular endothelial cells at the site of infection. Neutrophils have been shown to upregulate their surface expression of myeloperoxidase (MPO) in response to stimulus [15, 16]. Glycovariants of surface MPO are thought to bind to E-selectin [17] and maybe part of the mechanism that allows the movement of the neutrophils from the circulation into the mammary gland. Treatment of cows with PEGg-CSF can cause shedding of surface CD62L and up-regulation of cell surface MPO in neutrophils [18]. Experimental infection of the mammary gland has resulted in the appearance of neutrophils in the milk with the high surface level of CD62L and MPO, suggesting their translocation from the blood into the mammary gland of infected cows [18].

When they encounter a pathogen, neutrophils have multiple antimicrobial mechanistic weapons at their disposal. They can produce reactive oxygen species, phagocytose the bacteria, or eject their genomic material to capture the bacterium in what are called Neutrophil Extracellular Traps (NETs) that contain antimicrobial proteins [19-21]. The presence of neutrophil NETs in milk from infected cows can be observed by DNA stains of the milk fat. Of the three antimicrobial mechanisms employed by neutrophils, NETs have been shown to have a longer efficacy in milk than the others [20].

While antibiotics are the most common treatment for mastitis cases, alternative approaches do exist including preventative cytokine therapeutics such as pegylated granulocyte-colony stimulating factor (PEG-gCSF) (Imrestor/Pegbovigrastim, Elanco, IN USA). These alternative approaches have been shown to boost circulating neutrophil numbers, lower disease severity against mastitis challenge, and reduce the naturally occurring incidence of mastitis when administered during the periparturient period $[22,23]$.

\section{Case presentation}

We describe the case of a three-year old Holstein dairy cow (1428) who presented with a naturally-occurring, subclinical mastitis infection in her left hindquarter, approximately two months into her first lactation. Milk samples from cows in our research herd are periodically monitored for bacterial growth and changes in SCC (Somatic Cell Count) to monitor animal and udder health. Additional samples are collected if naturally occurring mastitis is suspected or for various scientific uses. Cow 1428 was born and raised on the USDA campus within the Holstein research herd. Mastitis was observed at a routine daily milking and culture of the sample was performed. Milk from quarters of interest was aseptically collected, by hand milking, and SCC sample values were determined by Dairy Lab Services (IA, USA). For bacterial counts, aseptically collected milk samples were plated on Trypticase Soy Agar with 5\% sheep blood plates (BD Biosciences, CA, USA Cat. No.221261), and incubated overnight at $37^{\circ} \mathrm{C}$, prior to colony counting. An isolated colony was typed by the Iowa State University Veterinary Diagnostic Laboratory (ISU VDL) and identified as $S$. aureus. The $S$. aureus strain was sequenced and designated as SA1428 [24]. The infection remained subclinical, with no identifiable drop in milk yield, no visual signs of inflammation including teat hardening, redness, or milk chunkiness, but was continuously identifiable by moderately increased SCC and bacterial culture. Multiple SCC and bacterial counts were determined over the course of several months. At the initial detection of the infection SCC in the infected quarter were $3.8 \times 10^{6}$ cells $/ \mathrm{mL}$ with bacteria counts $>3000 \mathrm{cfu} /$ $\mathrm{mL}$. Other quarters had no detectable bacteria and SCC below $7.5 \times 10^{4}$ cells/ mL. Cow 1428 was not isolated from 
the herd, however, no other cows became naturally infected with the novel $S$. aureus pathogen to our knowledge.

Cow 1428 was treated with antibiotics, daily for five days, with cephapirin sodium (ToDAY, Boehringer Ingelheim, MO, USA) twice daily, and additionally pirlimycin hydrochloride (PIRSUE, Zoetis, NJ, USA) once daily. In our herd, this treatment has been successful at clearing experimentally induced S. aureus infections (Newbould 305 strain). When antibiotics did not clear the infection (as confirmed by bacterial culture) an additional round of antibiotics was completed two months later, which also failed to clear 1428's infection. Numerous rounds of antibiotic treatment may not be a common commercial practice, but was appropriate within our research herd where previously we have been able to clear experimental $S$. aureus infections with this specific treatment and where milk is not used for human consumption. Interestingly, susceptibility testing of SA1428 by the ISU VDL, revealed susceptibility to several antibiotics (Ampicillin, Ceftiofur, Cephalothin, Erythromycin, Oxacillin, Penicillin, Penicillin/Novobiocin, Pirlimycin, Sulfadimethoxine, and Tetracycline). Mid-lactation, cow 1428 was treated off-label with a cytokine-based, PEG-gCSF therapy (Imrestor/Pegbovigrastim, Elanco, IN, USA), which was administered in two subcutaneous doses of $2.7 \mathrm{~mL}$ of $15 \mathrm{mg}$ PEG-gCSF 7 days apart. While on-label use is designed for periparturient administration, our group was interested if the PEGgCSF targeted neutrophil expansion would have an effect on 1428's chronic infection. After PEG-gCSF treatment, circulating blood neutrophils increased from $2 \times 10^{9}$ cells per liter of blood to $54 \times 10^{9}$ cells per liter of blood at their peak, 2 days post the second PEG-gCSF injection. In her infected quarter, cow 1428's SCC also increased, from $1.11 \times 10^{6}$ cells per milliliter of milk to $5.17 \times 10^{6}$ cells per milliliter of milk, peaking 4 days post the second PEGgCSF injection. Despite the increased presence of circulating neutrophils and milk SCC, cow 1428 did not clear the S. aureus infection. After being bred and confirmed pregnant, cow 1428 was dried off approximately 60 days prior to calving. In accordance with general dry-off practice, she was treated with cephapirin benzathine (ToMORROW, Boehringer Ingelheim, MO, USA). Seven days prior to cow 1428's calving date she was treated again with an injection of PEG-gCSF, and again on the day of calving, as directed by on-label use of the product. Despite this treatment, 1428's $S$. aureus infection presented immediately with the start of her second lactation.

We sought to characterize the infected mammary gland environment to identify phenotypes associated with SA1428 infection as compared to experimentally infected S. aureus. For the experimentally infected samples, we utilized resident Holsteins five weeks post experimental infection with $S$. aureus Newbould 305. For another ongoing study on the USDA National Animal Disease Center campus, eight Holstein cows were challenged by intramammary infusion in a single quarter with $150 \mathrm{CFU}$ of $S$. aureus (Newbould). Subclinical, chronic infections developed in all cows. Five weeks after challenge, the Newbould infected cow with consistently high SCC values, and the Newbould infected cow with consistently low SCC values had milk samples collected for comparison along with milk from 1428's naturally occurring infection. Over three consecutive days, 1428 's SCC for her infected quarter averaged $3.02 \pm$ $0.78 \times 10^{6}$ cells per milliliter of milk, the high SCC cow averaged $12.59 \pm 6.55 \times 10^{6}$ cells per milliliter of milk, and the low SCC cow averaged $0.24 \pm 0.08 \times 10^{6}$ cells per milliliter of milk.

From S. aureus infected quarters $100-150 \mathrm{~mL}$ of milk was collected into $50 \mathrm{~mL}$ conical tubes. Samples were spun for $40 \mathrm{~min}$, at $10,000 \mathrm{x} \mathrm{g}$, at $4{ }^{\circ} \mathrm{C}$ to separate for pelleted milk cells for flow analysis and milk fat. Top milk fat layers were scraped into separate tubes, washed with PBS and protease inhibitor, and frozen for subsequent NET analysis.

Milk from the centrifuged samples was poured off, and cell pellets were placed on ice and resuspended in $1 \mathrm{~mL}$ media (L-glutamine, 10\% FBS supplemented complete RPMI). Cell suspensions were layered over density gradients (Histopaque 1077, Sigma Aldrich, MO, USA, Cat No. 10771-500ML) spun for $20 \mathrm{~min}$ at $1500 \mathrm{x} \mathrm{g}$, and had buffy coats removed leaving a highly neutrophil enriched cell pellet. Cell pellets were washed once with PBS and live cell counts were determined by cell counter (TC20 automated cell counter, BioRad, CA, USA). We used flow cytometry to evaluate the surface expression of MPO and L-selectin on neutrophils sourced from milk from infected quarters. To compare MPO and L-selectin expression over a range of SCC, we sampled milk from the Newbould infected cows with the highest and lowest SCC to compare with milk from cow 1428. Live milk cells were washed and resuspended in flow buffer (BioLegend, CA, USA, Cat. No. 420201). Individual primary, secondary, and directly conjugated antibodies were added to cell suspensions and incubated at room temperature for $15 \mathrm{~min}$ in the dark, with a flow buffer wash step between each antibody set. Samples were run on a Becton Dickinson LSR II flow cytometer and all analyses were performed with FlowJo software (FlowJo LLC, Ashland, OR, USA). Neutrophil gating was determined by forward and side scatter. Live, singlet milk cells were gated for CD45 (Monoclonal Antibody Center, Washington State University, USA. Cat. No. BOV2039). CD $45^{+}$cells were separately assessed for MPO (BioRad, Hercules, CA, USA Cat. No. VPA00193) and CD62L (BioLegend, San Diego, CA, USA Cat. No. 304824) surface expression. Flow cytometry of milk 
derived neutrophils from the three cows showed that cow 1428 had the greatest MPO surface expression (Fig. 1a). Between the Newbould infected cows, the high SCC cow also showed higher surface MPO expression compared to the low SCC cow (Fig. 1a). Surface expression of L-selectin revealed comparable levels on 1428 and the high SCC Newbould infected cow, but both were reduced compared to the low SCC Newbould infected cow (Fig. 1b).

Neutrophils are known to produce NETs with activation which results in cell death. To capture information about NET-forming neutrophils, we stained milk fat for DNA as described previously [16], which is indicative of NET formation from all three cows. Microscopy showed that 1428 had the greatest NET presence (Fig. 1c), compared to both Newbould infected cows (Fig. 1d, e). DNAse treated and healthy milk fat controls are shown in Fig. 1f, g. Samples were analyzed via confocal microscopy imaging using a Nikon A1R+ laser scanning microscope and NISElements imaging software. Slide images are shown at the 20X objective, 75 numerical aperture, as imaged using a GaASP detector, 561 laser.

Cow 1428 was euthanized approximately 20 months after the first identification of infection by lethal injection of barbiturates by our institutional veterinarian. Gross pathology of the infected quarter of the mammary gland can be seen in Fig. 2a, b. The infected quarter was systematically sampled by obtaining samples from 12 different sites; 3 each from the proximal and distal gland body of the gland, 3 from the collecting duct region and 1 each from the gland cistern, teat cistern and streak

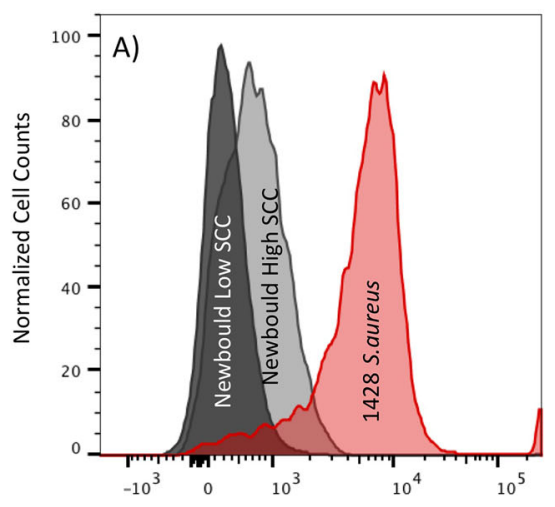

Myeloperoxidase (MPO) Surface Expression

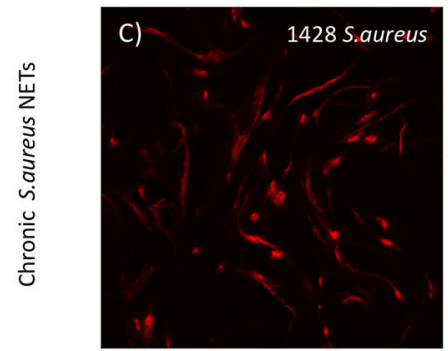

F)

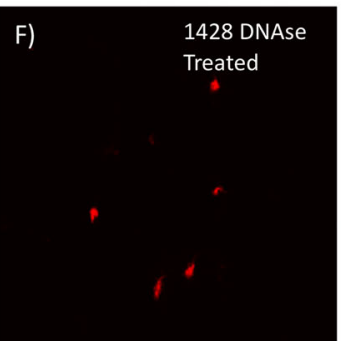

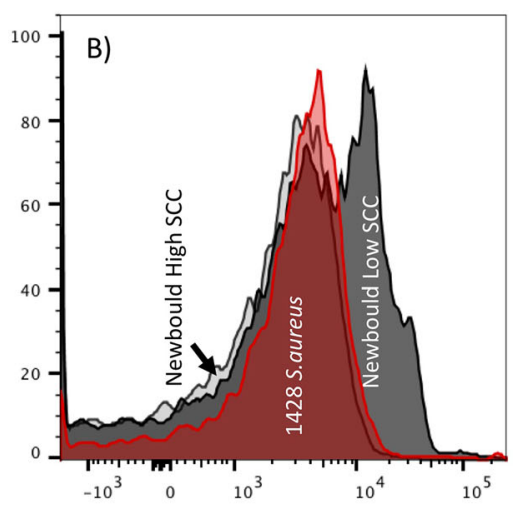

CD62L (L-selectin) Surface Expression
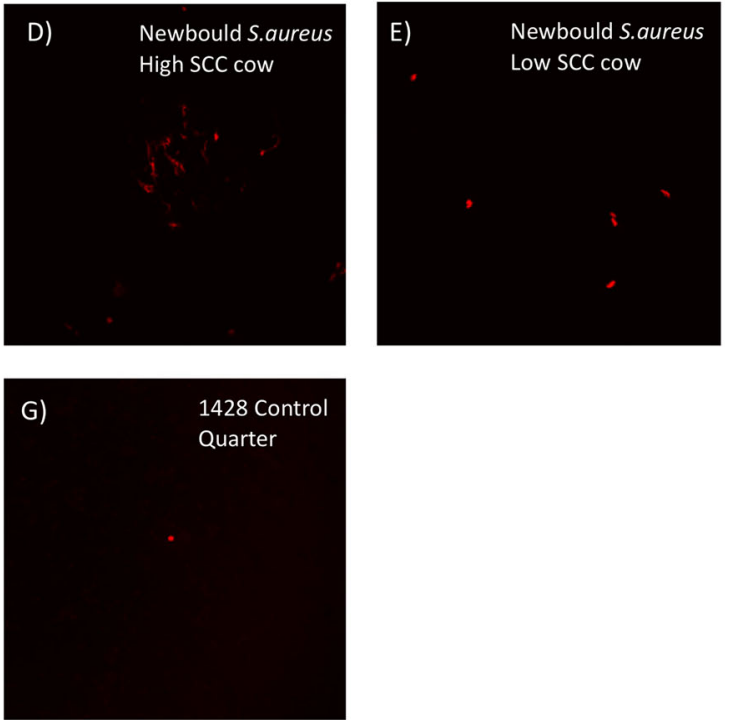

Fig. 1 Flow cytometry and microscopy of NETs sourced from chronically S. aureus infected milk from 1428 and two Newbould infected cows (high and low somatic cell responders). Flow Cytometry of neutrophils isolated from infected milk was analyzed for surface expression of (a) myeloperoxidase and (b) CD62L (L-selectin). The red histogram depicts cell isolated from 1428 milk, dark gray is from a chronic Newbould challenged low SCC cow, and light gray represents a chronic Newbould challenged high SCC cow. Milk fat was additionally evaluated for the presence of Neutrophil Extracellular Traps (NETs). (c) 1428 S. aureus infected milk fat shows increased NET presence compared to both high (d) and low (e) SCC cows challenged with Newbould. Control NET staining shows DNAse treatment of 1428's infected milk fat (f), and staining of clean healthy quarter milk fat from cow 1428 

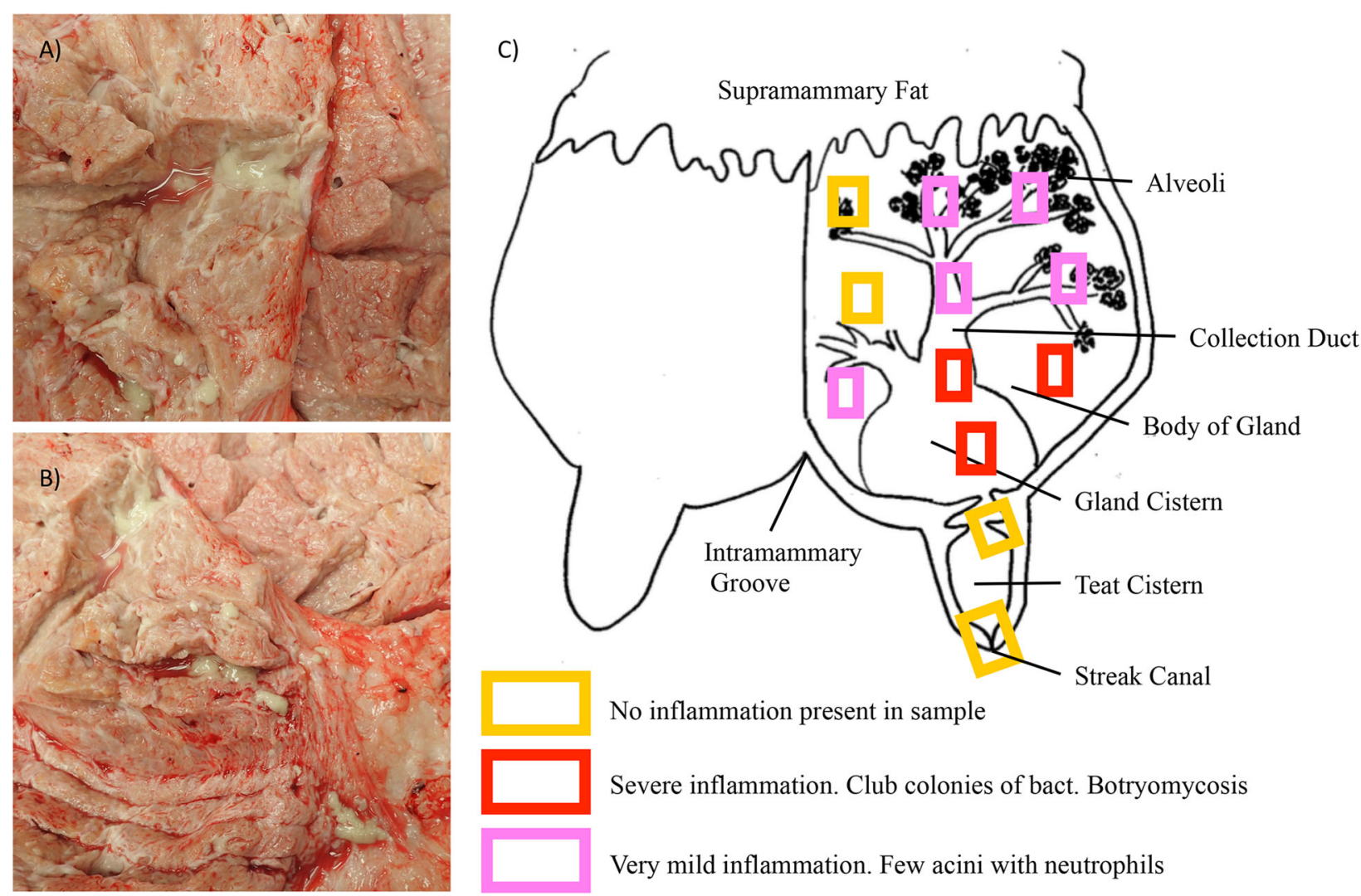

No inflammation present in sample

Severe inflammation. Club colonies of bact. Botryomycosis

Very mild inflammation. Few acini with neutrophils

Fig. 2 Gross pathology and necropsy collection outline detailing levels of inflammation. Gross pathology of 1428's infected quarter (a, b). Note multifocal purulent exudate found in abscesses surrounded by fibrous connective tissue. The mammary gland was sampled as detailed in (c), capturing tissue from physiologically meaningful regions of the mammary gland. Also depicted, general levels of inflammation found at each section level (c). Diagram in (c) adapted from [25]

canal as illustrated in Fig. 2c. Gross examination revealed multifocal abscesses and increased amounts of fibrous connective tissue, most notably in the collecting duct and gland cistern regions. Tissue samples $(\leq 0.5 \mathrm{~cm}$ thick) were fixed by immersion in $10 \%$ neutral buffered formalin for $24 \mathrm{~h}$, then transferred to $70 \%$ alcohol followed by standard paraffin embedding techniques. Paraffin embedded samples were cut to $4 \mu \mathrm{m}$ thick sections, transferred to Superfrost Plus ${ }^{\mathrm{mit}}$ charged microscope slides (Thermo Fisher, MA, USA) and stained with hematoxylin and eosin (H\&E). Adjacent sections were stained by the Hucker-Twort technique for visualization of Grampositive and Gram-negative bacteria. Microscopically, samples from the teat sphincter and teat cistern were normal, with minimal if any inflammation (Fig. 2c) and no bacteria present, confirmed by Gram stain. Samples from the gland cistern and collecting duct regions contained multifocal suppurative to pyogranulomatous infiltrates. Some regions contained distinct infiltrates of only neutrophils surrounding colonies of Gram-positive cocci embedded in a brightly eosinophilic, homogenous matrix, which radiated outward; interpreted to be Splendore-Hoeppli reaction
(Fig. 3a, b). In these same regions, there were also pyogranulomatous to granulomatous infiltrates arranged in nodules separated by prominent bands of fibrous connective tissue (Fig. 3c). These nodular infiltrates contained variable numbers of extracellular Gram-positive cocci. In the alveolar duct and body regions of the gland, numerous acini contained infiltrates of large numbers of neutrophils (Fig. 3d). In such acini, Gram-positive cocci were found both individually and in small colonies (Fig. 3e). Some glands were absent of inflammatory infiltrates, but one to several Gram-positive cocci could still be found adhered to or within epithelial cells (Fig. 3f).

To further document $S$. aureus strain SA1428, its genome was sequenced. The genome sequencing data have been deposited in NCBI Sequence Read Archive under accession number PRJNA609126. The de novo genome assembly is available at NCBI with the accession number CP048431-CP048432.

\section{Discussion and conclusions}

This unique case report sheds light on important host and pathogen interactions that should be further 

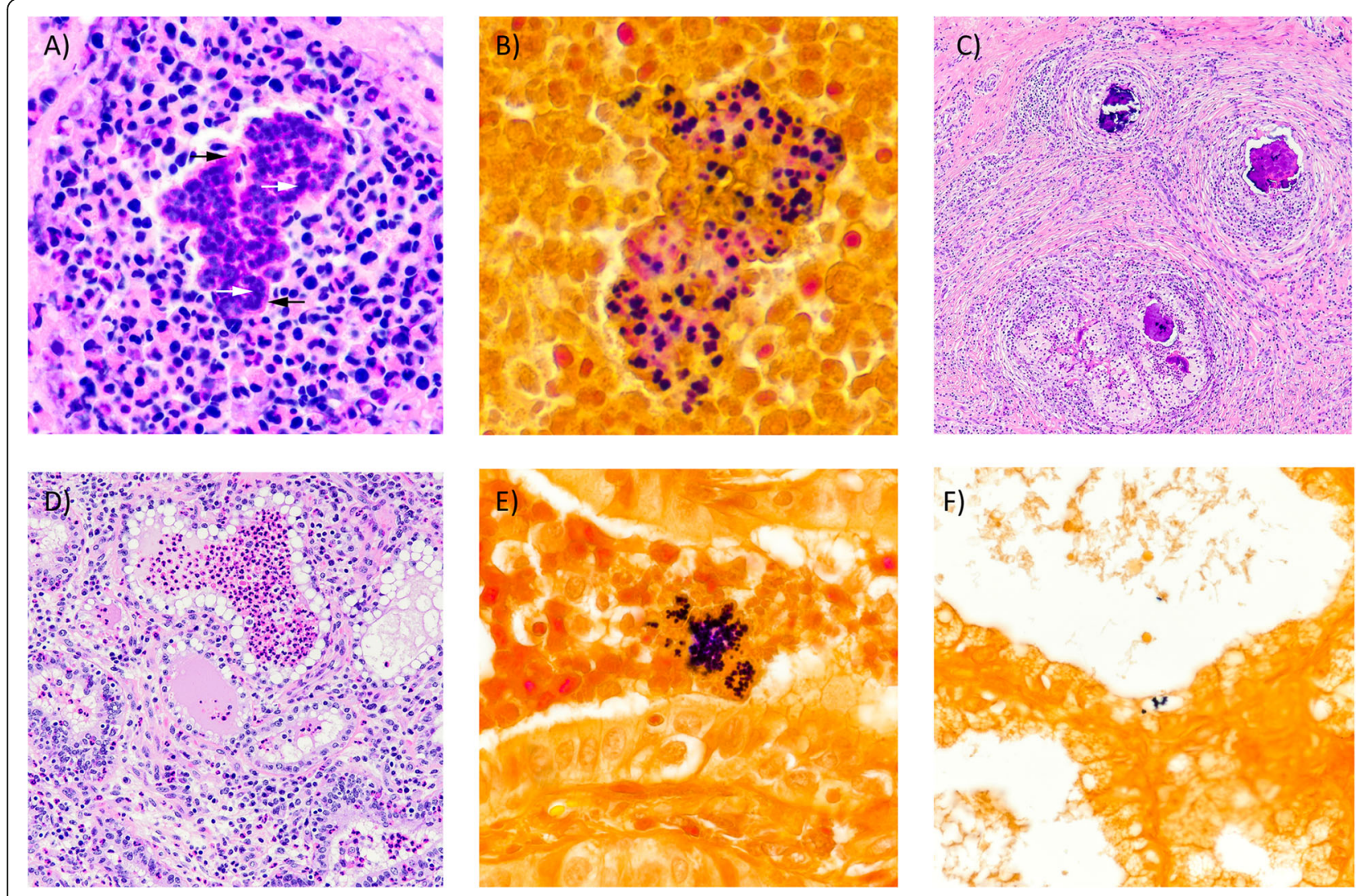

Fig. 3 Photomicrographs of mastitic quarter from 1428. (A) Pyogranulomatous infiltrate. Note colonies of basophilic cocci (white arrows) within brightly eosinophilic and radiating matrix of Splendore-Hoeppli reaction (black arrows). H\&E 20X. (B) Cocci within eosinophilic matrix are Grampositive. Gram stain 40X. (C) Granulomas with abundant peripheral fibrosis and central areas of dystrophic mineralization. H\&E 4X. (D) Acini containing numerous neutrophils. H\&E 10X. (E) Intraluminal Gram-positive cocci within acinus. Gram stain 40X. (F) Intracellular Gram-positive cocci. Gram stain $20 X$

investigated to be utilized in the development of mastitis treatment and preventative technologies. The presence of heightened immune cell activation in the mammary gland identified by present neutrophils, but lack of bacterial clearance, raises questions about the mechanisms of inflammation regulation and immune escape strategies of $S$. aureus as a mastitis causing pathogen. Low cure rates of $S$. aureus mastitis have been attributed to components of host and pathogen genetics, environmental exposure, and antibiotic resistance [26]. Additionally, while it's known that $S$. aureus can evade neutrophil killing and gain intracellular access to epithelial cells [26], much more needs to be understood about why the immune response is ineffective and how $S$. aureus escape mechanisms function. In this work we demonstrate a correlation between infections caused by two strains of $S$. aureus and differences in surface expression of proteins of interest on milk neutrophils. Milk neutrophils sourced from cow 1428 had substantially increased surface expression of MPO (Fig. 1a), which has been associated with cell activation [16] as well as accumulation within mastitic mammary glands [18]. Also consistent with neutrophil activation, levels of surface CD62L were comparable between 1428 cells and the high SCC Newbould cow, but both appeared to have increased shedding of CD62L compared to the low SCC cow (Fig. 1b). These observations are consistent with the role of CD62L as an adhesion molecule important for the targeting cells to the site of infection. These observations are also supportive of the hypothesis that MPO expressed on the cell surface may be a ligand for E-selectin and potentially plays a role in cell migration to localized infections. Lastly, imaging showed more NETs present in 1428's milk fat than in either of the Newbould challenged cows (Fig. 1c, d, e). Collectively these findings suggest that cow 1428 had heightened neutrophil activation within the mammary gland compared to cells from experimentally infected animals. It is also clear that this activation is not driven strictly by accumulated cell numbers as the high SCC Newbould infected cow had four-fold higher SCC numbers than 1428. Of interest, between the two Newbould experimentally-infected animals, the high SCC Newbould infected cow had higher surface expression of MPO compared to the low SCC 
Newbould infected cow (Fig. 1a), reduced surface expression of CD62L (Fig. 1b), and increased NET presence (Fig. 1d,e), which is supportive that these parameters are capturing biological activation. These findings should be further validated in the context of hypothesis driven experimental studies.

Many different strains of $S$. aureus exist that are capable of causing mastitis in dairy cattle. Variations in mastitis-causing strains include differences in the genotypic expression of virulence factors, biofilm production, cellular infiltration, and antimicrobial activity [27]. Comparison of an infection by SA1428 and SA Newbould highlights the phenotypic variation between strains that can be observed, both in terms of host immune cell response and response to antibiotic treatment; Newbould being successfully cleared and SA1428 persisting. The antibiotic susceptibility results of $S$. aureus SA1428, but failure to treat in vivo, suggests that the persistence of 1428 's infection may be contributed to physical escape by the bacteria. Histologically, inflammation of 1428's infected quarter can be considered chronic in nature with pyogranulomatous and granulomatous lesions and increased fibrosis. The largest numbers of Gram-positive cocci were seen within the eosinophilic matrix of the Splendore-Hoeppli reaction associated with pyogranulomatous lesions and the nodular granulomatous infiltrates surrounded by large bands of fibrous connective tissue. Both settings provide protection from antibiotic treatment.

The naturally occurring, chronic case of $S$. aureus mastitis of cow 1428 describes the identification of strain SA1428, and describes an associated treatment-resistant phenotype. Our unique evaluation of activation levels of mammary sourced neutrophils, and detailed look at weakly characterized histology phenomena, contributes to the general knowledge of the behavior of chronic $S$. aureus infections, and offers several opportunities for hypothesis driven research to explore these findings.

\section{Abbreviations \\ SCC: Somatic Cell Count; MPO: Myeloperoxidase; PEG-gCSF: Pegylated granulocyte-colony stimulating factor; NET: Neutrophil extracellular trap; H\&E: Hematoxylin and eosin}

\section{Acknowledgements \\ Our greatest appreciation goes to Duane Zimmerman, Tera Nyholm, Adrienne Shircliff, and Judi Stasko of the USDA Microscopy Service team, as well as to the animal and veterinary care staff for the excellent care of animals. Mention of trade names, proprietary products, or specified equipment do not constitute a guarantee or warranty by the USDA and does not imply approval to the exclusion of other products that may be suitable. USDA is an Equal Opportunity Employer.}

\section{Authors' contributions}

EJP wrote the manuscript and performed neutrophil characterization. MP was the case pathologist, responsible for necropsy sample collection, interpretation of histological results, and helped write and edit the manuscript. HM was responsible for the processing of sequence data. JDL and TAR helped interpret results, contributed to writing and editing the manuscript, and aided in designing characterization methods. The author(s) read and approved the final manuscript.

\section{Funding}

This research was funded solely by the USDA.

\section{Availability of data and materials}

The genome sequencing data for SA1428 has been deposited in NCBI Sequence Read Archive (accession number PRJNA609126), and the de novo genome assembly is available at NCBI (accession number CP048431-

CP048432). All additional datasets used and/or analyzed during the current study are available from the corresponding author on reasonable request.

\section{Ethics approval}

All animal procedures were done with animals owned by the USDA and approved by the National Animal Health Center Animal Care and Use Committee.

\section{Consent for publication}

Not applicable.

\section{Competing interests}

EC is editorial board member of BMC Veterinary Research. The other authors declare that they have no competing interests.

\section{Author details}

${ }^{1}$ USDA-ARS-National Animal Disease Center, Infectious Bacterial Diseases Research Unit, Ames, IA, USA. ${ }^{2}$ USDA-ARS-National Animal Disease Center, Ruminant Disease and Immunology Research Unit, Ames, IA, USA.

Received: 19 May 2020 Accepted: 18 August 2020

Published online: 15 September 2020

\section{References}

1. USDA-APHIS. Highlights of Dairy2007 part I: reference of dairy health and Management in the United States; 2007. p. 1-2.

2. Ismail ZB. Mastitis vaccines in dairy cows: recent developments and recommendations of application. Veterinary World. 2017;10(9):1057-62.

3. Linder M, Paduch JH, Grieger AS, Mansion-de Vries E, Knorr N, Zinke C, et al. Cure rates of chronic subclinical Staphylococcus aureus mastitis in lactating dairy cows after antibiotic therapy. Berl Munch Tierarztl Wochenschr. 2013; 126(7-8):291-6.

4. Hensen SM, Pavicic MJ, Lohuis JA, de Hoog JA, Poutrel B. Location of Staphylococcus aureus within the experimentally infected bovine udder and the expression of capsular polysaccharide type 5 in situ. J Dairy Sci. 2000;83(9):1966-75.

5. Hensen SM, Pavicic MJ, Lohuis JA, Poutrel B. Use of bovine primary mammary epithelial cells for the comparison of adherence and invasion ability of Staphylococcus aureus strains. J Dairy Sci. 2000;83(3):418-29.

6. Bianchi RM, Schwertz Cl, de Cecco BS, et al. Pathological and microbiological characterization of mastitis in dairy cows. Trop Anim Health Prod. 2019;51(7):2057-66.

7. Kim Y, Atalla H, Mallard B, Robert C, Karrow N. Changes in Holstein cow milk and serum proteins during intramammary infection with three different strains of Staphylococcus aureus. BMC Vet Res. 2011;7:51.

8. Kozytska S, Stauss D, Pawlik MC, Hensen S, Eckart M, Ziebuhr W, et al. Identification of specific genes in Staphylococcus aureus strains associated with bovine mastitis. Vet Microbiol. 2010;145(3-4):360-5.

9. Paape MJ, Bannerman DD, Zhao X, Lee JW. The bovine neutrophil: structure and function in blood and milk. Vet Res. 2003;34(5):597-627.

10. Burton JL, Erskine RJ. Immunity and mastitis. Some new ideas for an old disease. Vet Clin North Am Food Anim Pract. 2003;19(1):1-45.

11. Kehrli ME Jr, Harp JA. Immunity in the mammary gland. Vet Clin North Am Food Anim Pract. 2001;17(3):495-516.

12. Ivetic A. A head-to-tail view of $\mathrm{L}$-selectin and its impact on neutrophil behaviour. Cell Tissue Res. 2018;371(3):437-53.

13. Diez-Fraille A, Mehrzad J, Meyer E, Duchateau L, Burvenich C. Comparison of L-selectin and mac-1 expression on blood and milk neutrophils during experimental Escherichia coli-induced mastitis in cows. Am J Vet Res. 2004; 65(8):1164-71. 
14. Wang Y, Zhang AC, Ni Z, Herrera A, Walcheck B. ADAM17 activity and other mechanisms of soluble $L$-selectin production during death receptorinduced leukocyte apoptosis. J Immunol. 2010;184(8):4447-54.

15. Kindzelskii AL, Clark AJ, Espinoza J, Maeda N, Aratani Y, Romero R, et al. Myeloperoxidase accumulates at the neutrophil surface and enhances cell metabolism and oxidant release during pregnancy. Eur J Immunol. 2006; 36(6):1619-28

16. Powell EJ, Reinhardt TA, Casas E, Lippolis JD. The effect of pegylated granulocyte colony-stimulating factor treatment prior to experimental mastitis in lactating Holsteins. J Dairy Sci. 2018;101(9):8182-93.

17. Silvescu Cl, Sackstein R. G-CSF induces membrane expression of a myeloperoxidase glycovariant that operates as an E-selectin ligand on human myeloid cells. Proc Natl Acad Sci U S A. 2014;111(29):10696-701.

18. Putz EJ, Eder JM, Reinhardt TA, Sacco RE, Casas E, Lippolis JD. Differential phenotype of immune cells in blood and milk following pegylated granulocyte colony-stimulating factor therapy during a chronic Staphylococcus aureus infection in lactating Holsteins. J Dairy Sci. 2019; 102(10):9268-84

19. Brinkmann V, Reichard U, Goosmann C, Fauler B, Uhlemann Y, Weiss DS, et al. Neutrophil extracellular traps kill bacteria. Science (New York, NY). 2004;303(5663):1532-5.

20. Lippolis JD, Reinhardt TA, Goff JP, Horst RL. Neutrophil extracellular trap formation by bovine neutrophils is not inhibited by milk. Vet Immunol Immunopathol. 2006;113(1-2):248-55.

21. Reinhardt TA, Sacco RE, Nonnecke BJ, Lippolis JD. Bovine milk proteome: quantitative changes in normal milk exosomes, milk fat globule membranes and whey proteomes resulting from Staphylococcus aureus mastitis. J Proteomics. 2013;82:141-54.

22. Canning P, Hassfurther R, TerHune T, Rogers K, Abbott S, Kolb D. Efficacy and clinical safety of pegbovigrastim for preventing naturally occurring clinical mastitis in periparturient primiparous and multiparous cows on US commercial dairies. J Dairy Sci. 2017;100(8):6504-15.

23. Ruiz $R$, Tedeschi LO, Sepulveda A. Investigation of the effect of pegbovigrastim on some periparturient immune disorders and performance in Mexican dairy herds. J Dairy Sci. 2017;100(4):3305-17.

24. Lippolis JD, Putz EJ, Ma H, Alt DP, Casas E, Reinhardt TA. Genome Sequence of a Staphylococcus aureus Strain Isolated from a Dairy Cow That Was Nonresponsive to Antibiotic Treatment. Microbiol Resour Announc. 2020; 9(20):e00206-20.

25. Alany RG, Bhattarai S, S. P Devarajan PV. Intramammary delivery technologies for cattle mastitis treatment. In: Rathbone M, McDowell A, editors. Long acting animal health drug products. Advances in delivery science and technology. Boston: Springer; 2013. p. 295-327.

26. Barkema HW, Schukken YH, Zadoks RN. Invited review: the role of cow, pathogen, and treatment regimen in the therapeutic success of bovine Staphylococcus aureus mastitis. J Dairy Sci. 2006;89(6):1877-95.

27. Côté-Gravel J, Malouin F. Symposium review: features of Staphylococcus aureus mastitis pathogenesis that guide vaccine development strategies. Dairy Sci. 2019;102(5):4727-40.

\section{Publisher's Note}

Springer Nature remains neutral with regard to jurisdictional claims in published maps and institutional affiliations.

Ready to submit your research? Choose BMC and benefit from:

- fast, convenient online submission

- thorough peer review by experienced researchers in your field

- rapid publication on acceptance

- support for research data, including large and complex data types

- gold Open Access which fosters wider collaboration and increased citations

- maximum visibility for your research: over $100 \mathrm{M}$ website views per year

At BMC, research is always in progress.

Learn more biomedcentral.com/submissions 